\title{
ALTERIDAD Y ALIENIDAD DURANTE EL SIGLO IV: LOS OBISPOS CRISTIANOS ANTE LAS CONNOTACIONES INCLUSIVAS O EXCLUYENTES
}

\author{
Graciela Gómez Aso \\ Universidad Católica Argentina
}

\begin{abstract}
El tema del "bárbaro" ha concitado la atención del hombre Occidental desde la época de los primeros narradores griegos ${ }^{1}$ hasta nosotros.

En las últimas décadas, en particular desde la aparición de la obra de
\end{abstract} Daugé (1981), hemos reconocido en "lo bárbaro" un fenómeno propio del patrimonio cultural de la humanidad, en tanto se considere portadora de valores de civilización.

En la época clásica se manifestó cierta marginalidad física y ética (GARCíA MORENO, 2001, p.32) para con el bárbaro. En algunas de las obras romanas de la tardo-antigüedad, éstos eran considerados más próximos a las bestias salvajes que a verdaderos "hombres", no solo por su aspecto físico, sino sobre todo, por sus costumbres y estilo de vida.

La visión del romano sobre la barbarie parece ser la de un pueblo activo, voluntario, dominador, realista e idealista a la vez, con una gran pasión por la unidad, acostumbrado a luchar y a creerse eficiente y exitoso en la "guerra interior" como en la "guerra exterior". El bárbaro era, frente a esa realidad, el obstáculo, el adversario, el mal, la amenaza permanente, y también la materia a la que se debía transformar.

El universo espiritual romano lo hacía partícipe de una lucha cósmica. En ese contexto su concepción del bárbaro como "otro", se presentaba como audaz y dramática al mismo tiempo. No existía una visión monolítica de parte de los romanos. Su concepción del otro era, en efecto perfectamente equilibrada, por que era realista: se adecuaba a los hechos, a las circunstancias puntuales de la conquista.

El problema del otro era complejo, pues era en el fondo un problema de proporciones, de defectos y de cualidades, y también de mezclas diversas de mal y bien. Hay un otro que se podía aceptar, que se podía integrar, tras modificarlo y hay un otro que se debía rechazar. Más que alteridad se producía una alienidad. Roma más que ninguna otra sociedad se había apropiado de todo lo que el mundo exterior podía aportarle, pero también había rechazado y vencido todo aquello que hacía peligrar su propia civilización. Esta dialéctica continua entre apertura y cerrazón (GARCíA MORENO, 2001, p.394-395), pareciera fundarse en el sentido de la realidad y practicidad propiamente romanos 
De acuerdo con esta concepción, existían dos grandes categorías de posturas del romano para con el bárbaro:

1. Aquella en la que se presenta al otro como otro sin connotación incorporada: En el caso de los bárbaros se los conoce por su procedencia: Galli, Germani, Suebi, etc; y por los adjetivos correspondientes: gens, gentes, natio, naciones, genus, ingenum. También se pueden encontrar apelativos: hostis, hostes, etc.

2. Otra forma en la que se percibe la exclusión. Se apela al contraste, a la violencia, el ardor polémico, a la antítesis y en un contexto más vehemente al uso de términos sugestivos, susceptibles de tener un valor peyorativo: exterus, externus, alius, alienus, alienigena, alienigenus, con los que pareciera buscarse la diferencia, la separación. Se utiliza todo un vocabulario que designa especialmente al otro, lo designa no solamente en tanto que colectividad, individuos $\mathrm{u}$ objetos sino también en tanto que universo de valores $\mathrm{y}$ de conceptos negativos y en el plano filosófico se presenta al otro, como carente de ser. De acuerdo con esta forma se trata de rechazar o excluir al otro (GARCíA MORENO, 2001, p.396-402).

El problema, razón de ser de este trabajo, se circunscribe contextualizar estas categorias de análisis, provistas por Yves Daugé en su obra "Lo bárbaro" en función de las posturas que adoptaron, para con el bárbaro, los más importantes autores cristianos de la transición de la Romanizad a la Cristiandad, en particular aquellas que tan profusamente brindaron los Padres de la iglesia Occidental: Jerónimo de Estridón, Ambrosio de Milán y Agustín de Hipona.

\section{El uso del término bárbaro entre griegos y romanos}

Los griegos llamaban bárbaros indistintamente a los hombres, como a las ciudades que no pertenecían a la familia helénica.

En principio solo se refería a los hombres que no entendían la lengua. En sánscrito barbaras, var, varas, significa extranjero. Barbarus pareciera tener parentesco con balbus y balbutio, que significa incomprensible. De acuerdo con estos usos, eran bárbaros los que hablaban de una manera poco inteligible. Durante mucho tiempo los griegos tuvieron conciencia de formar de una manera única y absoluta una comunidad de raza, lengua, religión, derecho, cultura y costumbres superior a toda otra comunidad y de encarnar, gracias a una síntesis de cualidades sin igual, el tipo perfecto de hombre. Ya en la "política", Aristóteles afirmaba que "...la raza griega poseía a la vez el coraje de los pueblos nórdicos y europeos y las cualidades intelectuales de los pueblos de Asia; así que ella sería la medida de dominio en el mundo..." (Cfr. DAUGÉ, 1981, p.10).

El término bárbaro largo tiempo aplicado por los griegos a los romanos, parece haber tenido en su significado y aplicación el mismo desarrollo. Los romanos en principio entendían por bárbaro a todo aquel hombre que hablaba 
una lengua extranjera, reservada a los que no participaban de la civilización grecoromana, de la que Roma se enorgullecía de ser el centro. Esta expresión designaba en principio solo a los pueblos de costumbres connotadas como salvajes en la las provincias o en la periferia. Más tarde, durante el Imperio se dejó de confundir a los provinciales (peregrini o provinciales) con las naciones ubicadas cerca de las fronteras y que no reconocían la superioridad romana ni habían firmado con Roma ninguna alianza (FOEDUS) La situación de los bárbaros no puede ser confundida con la los sujetos extranjeros no ciudadanos (peregrini) que estaban ubicados en los límites del Imperio.

En principio los enemigos (hostis) y los extranjeros (peregrinus) eran connotaciones de igual significado. El derecho romano aplicó diferencias jurídicas, pues los hostis serán aceptados por el derecho de gentes (ius gentium). Los sujetos provinciales y los extranjeros (peregrini) fueron tratados como aliados. Esta excepción peregrini, no se extendió a los bárbaros de la periferia. De allí

Deducimos, que la condición de bárbaro era aún inferior a la de extranjero (peregrini) (DAREMBERG, SAGLIO, 1877, p.670).

En los siglos II y III del Imperio, las relaciones pacíficas con los bárbaros, no debía ser muy ordinaria porque Gaius - Ulpiano se ocupan de su reglamentación. Los bárbaros estaban sometidos al puro derecho natural, común a todos los hombres de esta cualidad.

El peligro de la invasión general de los bárbaros, a partir del III siglo tendió a agravar de hecho la posición de los bárbaros que quedaban en el Imperio (alienigeni). Los bárbaros propiamente dichos o alienigeni, eran tratados con un gran rigor. Algunos emperadores les permitieron a ciertas tribus, establecerse en el interior de las fronteras y conservar sus usos y costumbres, al mismo tiempo que se los sujetaba al cumplimiento de la ley romana. Varias de estas tribus fueron admitidas a cambio de servicio militar, bajo el título de beneficiarii, coloni, diditicii, foederati, gentiles (DAREMBERG, SAGLIO, 1877, p. 671-672).

El punto de vista de los romanos sobre los otros no es étnico o nacional como entre los griegos. Se trata para él, de una categoría del ser, de un elemento fundamental de la vida y de la historia. El otro debía ver a la romanizad como principio del bien, como expresión de la verdad y de una superioridad ontológica que se representaba en el conjunto de sus valores espirituales.

Analizando a los otros y a él mismo, el romano trataba de imponer su genio propio, que no era otro para el que el genio humano creador del orden y de la civilización que debía luchar contra todos los obstáculos internos y externos. En el romano se percibe una voluntad permanente de oposición entre romanidad y barbarie. Esto lo llevaba a situar el problema en un nivel a la vez étnico, cósmico y metafísico.

Para el romano, el bárbaro no constituía una especie diferente, sino un estado inferior (colectivo o individual) del hombre, una manera de ser defectuosa, 
inacabada, incompleta, no definitiva sino variable. El bárbaro como en principio el civilizado estaba sujeto a cambios y podía siempre evolucionar. El bárbaro podía acceder a la humanitas, y por esta vía podía darle sentido a la cultura romana (DAUGÉ, 1981, p.19-20).

\section{La visión de los escritores cristianos: alteridad y alienidad}

Durante los siglos IV y V el cristianismo había cobrado importancia puesto que estaba dispuesto a recibir la herencia del universo cultural romano, en franca decadencia.

Los cristianos como comunidad y la iglesia cristiana como institución del imperio eran conscientes del problema de la barbarie. Frente al bárbaro la intelectualidad cristiana se preocupó por conocer la antropología del bárbaro en la medida en que se pondría en contacto con la propia antropología del cristiano.

La ideología y la tipología judeo-cristiana, vivieron, durante la tardoantigüedad, inmersos en un universo teológico, imbuido de teorías acerca del mal, del pecado, del pecado original y de conceptos como los de paganismo, herejía, conversión, a los que se sumaban las especulaciones escatológicas y milenaristas. En los cenáculos cristianos las profecías y el Apocalipsis cobraron valor ante el ingreso masivo de pueblos bárbaros que podían fácilmente confundirse con figuras como las de Satán, los demonios e incluso el anticristo (DAUGÉ, 1981, p.376-377).

Las posturas que ganaron espacio en la vida intelectual de la elite eclesial, en particular entre los Padres de la iglesia eran aquellas propias de visiones apocalípticas acerca de la historia judeo-cristiana o en particular como aquellas posturas podían interpretarse en esa realidad de crisis que se vivían en la parte Occidental del Imperio romano.

Es atinado aclarar, que los Apocalipsis representan una literatura para un tiempo de crisis. Estos son, esencialmente, una revelación sobre el fin de los tiempos y en consecuencia, estos textos sólo se interesan por la historia pasada o presente en la medida en que estas preparan el fin de la historia (DELCOR, 1977, p.45). Gran parte de los obispos y escritores cristianos interpretaron esta circunstancia decadente y ruinosa como un mensaje que Dios le daba a sus hijos terrenales.

Así Lactancio, en consonancia con la visión de los autores romanos del fin de la República advertía a sus lectores:

La caída y decadencia del mundo tendrá lugar pronto, pero no ocurrirá mientras la ciudad de Roma permanezca intacta... (Lact. DI 7.25) ${ }^{2}$.

Durante el duro proceso de controversias entre los arrianos y los paganos ${ }^{3}$, se inflamó la postura de los autores cristianos, hasta tal punto, que Hilario de 
Poitiers, predijo en el año 364 "la llegada del Anticristo dentro de la próxima generación" (Hilarius Aux. 5.10).

Ambrosio, obispo de Milán, reconocido Padre de la Iglesia y ávido lector de autores clásicos, difundió la hipótesis de que la catástrofe de sus tiempos, podría llegar a ser una verdadera señal del fin del mundo. Ambrosio creía que la gran tragedia tenía dos aristas, por un lado, hablaba de los enemigos externos (hostes extranei) (MAZZARINO, 1961, p.45) a los que él asimilaba con los pueblos bárbaros llegados desde el lejano oriente:

Es un diluvio de pueblos cuyos orígenes son lejanos; una brusca plaga endémica en la que reposa el arca antigua, testimonio del primer diluvio (...) Pero, contra estos bárbaros salvajes, emergidos de la lejanía del desconocido oriente o del frío septentrión silencioso, que encarnan la potencia diabólica en el mundo... (HUBEÑAK, 1997. p.221)

Pero, por otro lado, hablaba de los enemigos internos (hostes domestici) como las pasiones, la primera de todas, la ambición de dinero y de dominio que habían alejado a los hombres del camino primitivo y en el fondo del derecho natural (MAZZARINO, 1961, p.45)

Pero hay guerras también, que el cristiano debe afrontar: las batallas contra la codicia y los conflictos de las pasiones: los enemigos internos son todavía más graves que los externos... (MAZZARINO, 1961, p.46)

En sus palabras apreciamos, su preocupación por los tiempos críticos en los que estaba inserto el hombre tardo-antiguo.

Posteriormente, otro Padre de la Iglesia, Jerónimo de Estridón, fue un testigo de excepción de la invasión de los hunos a Oriente. Al respecto, no trepidó en identificarlos con el sanguinario pueblo bíblico de Magog (V.T. Ez. 38.1; 39.20.), que según la tradición, había sido encerrado por Alejandro de Macedonia entre los montes del Cáucaso para evitar que estos seres monstruosos invadieran otros territorios y los asolaran con su crueldad (BOCK, 1988, p. 125-127). Sobre la fiereza demoníaca de los hunos agregó:

¡Aparta Jesús en lo sucesivo del orbe romano a semejantes fieras! (Cfr. Jer. Ep. 77.8. Ver BOCK, 1988, p. 125)

Sobre el masivo ataque de los visigodos acaudillados por Alarico a Grecia en el 395 dijo:

¡Cuántas vírgenes consagradas a Dios, cuántos hombres libres o nobles sirvieron de juguete a estas bestias! iLos obispos fueron hechos cautivos, los sacerdotes asesinados, al igual que los clérigos de cualquier rango; las iglesias destruidas, los caballos estabulados junto a los altares de Cristo, las reliquias de los mártires fueron desenterradas! (Jer. Ep. 60.16. Cfr. GARCíA MORENO, 2000, p.40) 
Como se ha podido observar la visión de algunos intelectuales cristianos, no sólo interpretaba la realidad crítica desde un cristal apocalíptico, sino que estaba teñida de connotaciones peyorativas que pretendieron excluir al bárbaro del universo cultural romano-cristiano.

En la generación intelectual cristiana posterior, se destacó la voz de Agustín el obispo de Hipona. La obra agustina esta inserta en una nueva realidad histórica, durante la primera década del siglo V (410), la ciudad de Roma ha caído en manos del visigodo Alarico. Este acontecimiento fue una bisagra en la interpretación de los nuevos tiempos. La Roma invencible y gloriosa de los tiempos paganos había sido sustituida por una Roma vencida y humillada, convertida al cristianismo. La elite pagana tomó este hecho como una clara muestra de venganza de los dioses antiguos.

La tesis agustina, re-significó la interpretación apocalíptica. La Iglesia, debía incluir en su seno a todas las etnias, incluso, las entonces consideradas bárbaras, y apartar la cizaña, el nuevo pueblo de Magog: los paganos:

Ahí véis, dicen los paganos, que perece Roma en los tiempos cristianos. Quizá no es esto la desaparición de Roma; es quizá un azote y no una ruina; tal vez no perezca Roma si no perecen los romanos; y no perecerán si bendicen a Dios; perecerán si le blasfeman. (Aug. Ser. 81)

Si los bárbaros eran “...un azote, no una ruina” (August. Ser. 81), se podía interpretar que eran un castigo de Dios, un mensaje del cielo que le permitiría abrir los ojos a los descarriados y que los motivaba a ingresar a la comunidad cristiana.

En la misma línea interpretativa, encontramos a Rufino de Aquileia y Paulo Orosio,

Para Rufino, continuador de la obra de Eusebio de Cesarea, los bárbaros eran semina fidei y por tanto fundamentales en el plan divino de salvación, puesto que por su número y difundida expansión territorial podrían constituir una militia Christi que permitiría a los cristianos dominar a sus adversarios más enconados. Rufino no sólo realizó una relectura del viejo problema de la valoración del "bárbaro" sino también de la relación entre Cristianismo e Imperio romano y de éste con los bárbaros marginales (GARCÍA MORENO, 2001, p.41). Rufino introdujo la noción de bárbaro como herramienta político-religiosa de la Cristiandad en consolidación.

Paulo Orosio, el sacerdote-historiador español, tan cercano a Agustín pareció poner todas sus esperanzas en el foedus entre los bárbaros pasibles de conversión y el Reino de Dios. En este pacto de los cristianos se percibiría un

...gran tamiz, por el cual, de toda la masa del pueblo romano, como si de un gran montón de trigo se tratase, pasaran por todos los agujeros, saliendo de los escondidos rincones de todo el círculo de la ciudad, los granos 
vivos(así) (...) fueron aceptados todos aquellos granos del previsor granero del Señor que creyeron poder salvar la vida presente. (Or. 7.39.13-14)

\section{Conclusiones}

Tal como se ha podido apreciar la otredad como fenómeno complejo nos ha quedado evidenciada en un puñado de textos de autores cristianos. Aquellos hombres, romanos y cristianos al fin, fueron partícipes de una época de vertiginosos cambios; cambios que los condicionaron a una escritura entre eclesial y vivencial. En algunos casos se observan escritos que parecieran haber emergido del dolor, más que de la razón.

Entre los primeros escritores cristianos predominó la postura excluyente hacia "lo bárbaro". El universo del bárbaro era una masa informe que sólo refería a diferencia en los patrones de Civilización. El bárbaro formaba parte de un fenómeno diferente, cultural y políticamente y por su sola condición de diferente, de enemigo. El término bárbaro estaba sujeto a connotaciones negativas. La carga peyorativa, que se observa en la palabra de estos Padres de la Iglesia Occidental, parecía propia de un romano-pagano inflamado de patriotismo.

Entre los primeros Padres el bárbaro era tan negativo como un pagano o un hereje.

En Agustín y Paulo Orosio se percibe un cambio substancial. En ellos, pero particularmente en el obispo de Hipona, pareciera haber una necesidad ideológico-política de rearmar la teología política de esos tiempos de crisis, con nuevas piezas. Los paganos y los herejes serían los nuevos enemigos de la cristiandad en consolidación y en sus escritos lo reafirma permanentemente.

El cambio de postura se evidenció en las obras de Agustín (Civitate Dei) y Orosio (Historiae Adversus Paganus).

En la obra de Agustín se preanuncia una nueva época en la cual Roma, como capital de la cristiandad sería la cabeza del nuevo orden Occidental.

En ese contexto "los otros" son pueblos sin connotación, sin calidad de excluidos. El bárbaro es un "otro" pasible de incorporación en la Cristianitas. Orosio sugerirá que los bárbaros deberían ser la Militia Christi que defendiera a la Cristianitas de los nuevos enemigos: paganos y herejes.

La suerte estaba echada y con este pensamiento se sembró una tendencia que por vía de los monjes de los siglos posteriores sería moneda corriente.

El camino de la conversión de Europa estaba abierto. Las raíces de Europa, cristianas al fin, se reforzaron con esta nueva alianza. Mal que le pese a Edward Gibbon (2001), los cristianos y bárbaros, renovaron a una Roma moribunda y en pocos siglos de Cristianitas, Europa estaba en pie. 


\section{Alteridad y alienidad durante el siglo IV}

\section{Fuentes}

HILARIO DE POITIERS. Contra los arrianos, V, 10.

JERÓNIMO. Epístola.

LACTANCIO. Instituciones Divinas, VII, 25.

OROSIO. Historias, Libro VII, cap, 39, 13-14.

SAN AGUSTÍN. Sermón 81. (in: HUBEÑAK, F. Roma el mito político. Buenos Aires: Ciudad Argentina, 1997).

\section{Bibliografía}

BOCK, Susana. Los hunos: tradición e historia (en Antigüedad y Cristianismo). Murcia: Universidad de Murcia,. 1988.

DAREMBERG, MM. CH, SAGLIO, Edm. Dictionnaire des antiquités grecques et romaines. Paris: Hachette, 1877.

DAUGE, Yves Albert. Le Barbare. Recherches sur la conception romaine de la barbarie et de la civilisation. Bruxelle: Latomus, 1981.

DELCOR, M. Mito y tradición en la literatura apocalíptica. Madrid: Cristiandad, 1977.

GARCÍA MORENO, Luis A. La invasión de los bárbaros (siglos V-VI). Madrid: Real Academia de Historia, 2001.

GARCÍA MORENO, Luis. "La invasión de los bárbaros (siglos V-VI)", en: Tópicos y realidades de la Edad Media II, Real Academia de la Historia, 2000, p.40.

GIBBÓN, Edward. Historia de la decadencia y caída del Imperio Romano. Barcelona: Alba Editorial, 2001.

HUBEÑAK, F. Roma el mito político. Buenos Aires: Ciudad Argentina, 1997.

MAZZARINO, S. El fin del mundo antiguo. México: UTEHA. 1961.

\footnotetext{
Notas

${ }^{1}$ Cfr. Heródoto, Los nueve libros de la Historia; obra en la cual se utiliza por primera vez este término con el cual el autor, delineó el perfil de los otros a la cultura griega.

2 Lactancio, retor romano nacido en Nicomedia. Fue maestro de Crispo, hijo de Constantino el grande.

${ }^{3}$ Entre los años 337 y 359, la herejía arriana se difundió masivamente por todo el Imperio gracias a la labor del emperador Constancio. El mismo Jerónimo de Estridón dijo "el mundo gimió de verse arriano". El arrianismo fue definitivamente derrotado en el Oriente recién durante el reinado del hispano Teodosio. El Concilio de Constantinopla (381) ratificó el credo de Nicea como la profesión ortodoxa de la fe cristiana. En relación al paganismo, sabemos que fue revalorizado por el emperador Juliano, quien se enfrentó severamente a los cristianos. La controversia religiosa provocó acalorados enfrentamientos entre los pensadores paganos y los teólogos cristianos que, como en el caso de Hilario de Poitiers, vertieron en sus círculos intelectuales.
} 